\title{
Group therapy for victims and perpetrators of incest
}

\author{
Estela Welldon
}

Abuse is an inter-generational problem. Abusers have been damaged in childhood by abusive action perpetrated on them, usually by their parents but sometimes by other significant adults. At times, in becoming adults, the early emotional damage can manifest into psychopathological features, including perversions or paraphilias and perpetration of abuse against children.

People suffering from perversions present great difficulties for psychiatrists, one of which is based on these individuals' inability to intersperse a thought process before they commit the perverse action. Treatment has often been considered at best unrewarding, at worst impossible. Many sufferers encounter forensic psychiatrists in the course of brushes with the law, and many spend much of their lives in prison. When such people present a threat to the community, custodial care may be the only realistic option. However, punishment and incarceration are unlikely to have any effect upon the perversion.

\section{Forensic psychotherapy}

One of the aims of forensic psychotherapy is to enable both victims and perpetrators of abuse more fully to understand the antecedents of their behaviour and to take responsibility for their actions. Without doing so, there is no possibility of change and healthy maturation, or of remorse and reparation.

In recent years recognition of incest and sexual abuse has led to the development of services for survivors (Ashurst \& Hall, 1989), and acknowledgement that such traumas are implicated in much psychiatric illness. McCarthy (1982) criticised the contribution of psychoanalysis to psychiatry and allied professions; locating the theme of incest in the world of unconscious fantasy has deflected attention away from the reality of incest and delayed the discovery of sexual abuse within the family. Treatment programmes for abusers are rarely available within the National Health Service (NHS).

\section{Treatment}

For the past 60 years the Portman Clinic, part of the Tavistock and Portman Clinic NHS Trust, has been treating people who suffer from social and sexual deviations with individual or group analytical psychotherapy.

We are aware that our subjects are very much in need of three structures: fellow subjects, therapists and institutions. All are deeply related in their mental representations, which constitute a process of healthy triangulation. Because of their fears of intimacy in a one-to-one situation these people form a strong transference to the clinic as an institution. The setting is of utmost importance for both therapist and the subject whose problems involve acts against society, and this is better served within the NHS. The therapists' inner knowledge that the state is paying for their professional services becomes invaluable while working with this subject population.

Many people, including medical and legal professionals, assume that the people that we treat arrive here after their conduct has been discovered and a court has ordered treatment. This conclusion is partly based on the notion that sexual deviants have no insight and experience no shame. This is seldom true. Most of our subjects refer themselves, seeking treatment because of their tremendous loneliness, despair and desolation. They want to understand why they experience the compulsion to commit inexplicable acts and they often initiate

Estela Welldon is a consultant psychotherapist at the Portman Clinic (8 Fitzjohns Avenue, London NW35NA) and Honorary Senior Lecturer in forensic psychotherapy at University College, London (UCL). She is the Director of the UCL Diploma Course in Forensic Psychotherapy and Honorary President of the International Association for Forensic Psychotherapy. She is a member of the Board of Directors of the International Association for Group Psychotherapy and Chair of their Nominating Committee. 
contact by writing. They are usually insecure, inadequate and profoundly ashamed.

Another relevant stereotype is that in which women are victims and men perpetrators. When men are sexual abusers all sorts of different agencies, social and medical, intervene and very soon the police are called in. By contrast, the female offender finds it very difficult to get a hearing. Nobody wants to hear about her predicament, and nobody takes her too seriously. This happens even in group therapy where she finds that other abusers minimise her problems.

Group analytical psychotherapy is frequently the best form of treatment, not only for severely disturbed sexual and social deviancy but also for sexual abuse, in treating both the perpertrators of abuse and the victims of sexual abuse. Victims and perpetrators of incest share, by nature of their predicament, a history of an engulfing, intense, inappropriate, distorted, physical and sexual relationship of a highly secretive type within the family situation. Subjects' psychopathologies are the product of severe traumas and early learnt survival mechanisms. Group analytical therapy breaks through patterns of self-deception, fraud, secrecy and collusion which are invariably present in these cases. The amount of fear, rejection and humiliation which such people experience when confronted in a group therapy session with their secrets and shame is difficult to convey.

\section{Assessments}

It is important to make a differential diagnosis between incest parents and paedophiles in order to make accurate risk assessments and treatment recommendations. The DSM-IV classification (American Psychiatric Association, 1994) relates only to children victims of sexual abuse (995.5) and not to incest perpetrators. The distinction I have drawn, therefore, is based in my clinical experience.

While both incestuous parents and paedophiles involve themselves in child abuse and have had a traumatic early childhood, their presenting problems and surrounding circumstances are quite different. Incestuous parents have been able to achieve a fully developed relationship with another adult and to have a family. In contrast, paedophiles target primarily minors, and they are not engaged in adult relationships. Incest may be the outcome of dysfunctional family dynamics, often including an external event, such as a pathological bereavement. Instead, paedophiles do not present significant changes in their behaviour towards children related to external circumstances.
Incestuous fathers shift from wife to offspring, whereas paedophiles target women for their offspring. Furthermore, paedophiles have intense fears of relating to their peer group - both men and women. Their attitude towards the children involved is marked by intense externalisation, rationalisation and justification of their actions, making themselves believe that initiation to sexuality by adults is a healthy process. Paedophiles also claim to be completely unaware of the serious short- and long-term consequences to the children they have abused. Instead, incestuous parents are usually more aware of the long-term consequences produced by their actions, especially when they are taken into therapy.

Attitudes towards treatment are also different. Incestuous parents are often more motivated and frequently we see couples who come for treatment because of their incipient awareness of their need for understanding and professional help. This characteristic is seldom found in paedophiles. In practical terms, risk assessment and dangerousness are quite different for the two groups, so far as the two categories do not overlap. Incestuous fathers, on the whole, do not present future danger to other children, whereas paedophiles, often regardless of treatment and management, can be potentially dangerous in the future to children in general. Incest perpetrators have, if properly assessed and treated, a better prognosis than paedophiles.

Assessments of victims and perpertrators of abuse can easily trigger off emotional responses in the professionals, which may interfere with clear and unbiased treatment recommendations and are at times a re-enactments of early family situations. Sinason (1991) has described how the therapist's most painful interpretations were connected with trauma of an abusive nature and the difficulties in linking internal and external worlds.

The victims may succeed in making the therapist feel not only protective but also possessive about them, which could lead to the victim feeling favoured and unique in individual treatment (see Box 1).

Box 1. Therapists' feelings towards victims and perpetrators of incest

Victims

Protective

Patronising

In empathy and in identification

Uniqueness in understanding

Perpetrators Judgmental, non-therapeutic

Angry and sadistic

Trapped as a consenting child 


\section{Case example - Patricia}

During an assessment I felt protective of Patricia, an incest victim, and had the idea that the only person capable of fully understanding her was myself. At that point, I became aware that my initial response was in itself a contraindication for offering individual therapy. When I offered her group therapy, she was terrified at the prospect of having to confront and be confronted by so many strangers about her secret but was able to understand the reasons for this recommendation.

When dealing with the perpetrators, the therapist may feel cornered or blackmailed by confidentiality issues which may provoke feelings of collusion. Alternatively, the therapist might feel either like the consenting child or the seductive parent in the incest situation. In either situation, dynamic therapy meaning internal change - is in real jeopardy.

\section{Case example - Keith}

Keith was referred for treatment after the disclosure of his incestuous relationship with his stepdaughter. I saw him for several diagnostic interviews. These were beset with complications as all the different agencies involved demanded information about his activities. I was placed in a double-bind situation, first because of his demands for immediate treatment, and second because of his request for complete confidentiality. I began to feel cornered and blackmailed into giving him treatment in the utmost confidentiality which actually in this particular case meant secrecy. I became deeply aware of the transference-countertransference issues involved in 'incest with a consenting child'. These were very powerful feelings. At times I would feel like the child keeping quiet about it all; at other times, I would feel like the controlling and exploitative parental figure. After a great deal of careful thought I decided to offer him group therapy, a suggestion which first surprised and then enraged him. I gave him time to think about it, and tried to explain to him clearly why this would be the most suitable therapy for him: secrecy between parent and child is a key pathological trait in incest, which in group therapy is no longer available. Everything is open to everyone. A few weeks later it was my turn to be surprised when he accepted my recommendation.

Secrecy is pervasive and it may be disguised as confidentiality, threatening the therapeutic process in individual psychotherapy, re-enacting a symbolic incest and recreating an ineffectual locked-in stalemate position between two people.

\section{Importance of secrecy}

Because secrecy is deeply ingrained, it gives rise to threatening behaviour, violence, inability to think, lack of trust, trespassing of the generational differences (stolen childhood) and the victim feeling both abused and favoured.

Workers of all disciplines involved in cases of incest frequently find it difficult to maintain a detached professional stance. They tend to take sides, usually becoming emotionally bound to the victims. Additionally, they feel punitive towards the perpetrators. In their distress, they lose their understanding of the dynamics of what is happening. For example, a social worker dealing with the mother becomes so involved in supporting her that she loses sight of the mother's parenting inadequacies (Trowell, 1996). At other times professionals become so indignant that they fail to see that victims who become perpetrators experience a conscious or unconscious desire to take revenge for the pain inflicted upon them. These victimperpetrators believe they are creating a situation in which justice is satisfied. Actually, however, they are identifying with their aggressors. In somewhat similar ways, the professional workers often identify with the victims. Supervision has an important role in clarifying these issues, enabling therapists to avoid such pitfalls.

\section{Countertransference}

A group treatment approach allows a new transfercountertransfer process to take place for people who present problems related to violence and secrecy in the family. Trust towards peer members (sibling figures) is facilitated, and exclusive reliance on the therapist (parental figure) is discouraged. Group members open up and overcome the taboo of secrecy.

Group treatment of both victims and perpetrators of incest together (but not related) offers unexpected qualities of containment and insight that are virtually impossible in a one-to-one situation (Welldon, 1997). Perpetrators become deeply aware of the extensive long-term consequences of their actions. When confronted by the other members mirroring their victims' predicaments, it provides an opportunity for reflection, so that they can see how they experience themselves only as parts of their parental figures and their inability to see themselves as separate human beings. Every member experiences a powerful sense of belonging to the group. Throughout treatment the subjects gain a capacity for self-assertion, emotional growth, independence and individuality. They see themselves and others developing into respected individuals with self-esteem that is acknowledged by others and by themselves. They are not only 
allowed but encouraged openly to express anger and frustration which has been kept hidden for a long time. This encouragement comes especially from group members who have gone through similar predicaments and who are now ready to leave (see Box 2).

It is not uncommon to observe that females with a history of early incest may behave from the very start in the group as pseudo-ideal assistants to the therapist. Even those who have never been familiar with unconscious processes seem to discover immediately pseudo-appropriate ways to help the therapist-mother-father keep the group-family together. This is exactly what happened when Patricia joined the group; she started behaving as the ideal assistant to the therapist, even though she had never previously been in any kind of psychotherapeutic treatment. She fulfilled perfectly the role of the incest victim who tries to keep the family together. Fellow subjects often react with surprise and bewilderment at this show of false maturity. Later, this is replaced with competitiveness. When interpretations are offered to the effect that the newcomer is only repeating a pathological pattern learnt early in life, other members of the group seem relieved by this understanding but it is then the turn of the pseudo-helper to be filled with rage at this interpretation. After all, she is 'doing her best'; why is she being so 'harshly criticised'? Our group therapy programme has provided new understanding of the complexities of abuse, though we are still far from understanding everything.

A few months after starting group treatment Patricia was in tears telling us of her extreme humiliation on her recent visit to her parents who, despite knowing that she was a vegetarian, confronted her on Saturday morning with an enormous breakfast of sausages and bacon, specially cooked by her father, which she reluctantly, but acquiescently, ate.

Whereas previously Keith and Patricia had been unable to make any connection, even refusing eye

Box 2. Why group analytical psychotherapy for both victims and perpetrators of incest?

Secrecy is at the root of the problem-groups inhibit secrecy

The group offers a family-social microcosm where every member knows about the secret

Trust towards siblings is facilitated

Exclusive reliance on the parental figure (therapist) is discouraged

Expression of anger and revenge is facilitated contact, they were now in open confrontation with one another. Keith became suddenly aware of the long-term consequences of the incest when he indignantly questioned her inability to assert herself and her compulsion to give in to her father's requests. Suddenly and quite unexpectedly a complete understanding of their own respective roles and of the implications was available to us all. We all became aware that incest is much larger than life, that its power is not only physical, sexual or erotic. This secret union provides both partners with a 'uniqueness' which it is almost impossible to describe. It gives as much as it takes away.

It is also clear that victims, who may at the start be quiet and compliant, have much anger to express, anger that they have never felt free to display before. This is fundamental for them in being able to achieve any real change. It is essential to make the distinction between anger expressed in a straightforward manner, leading to self-assertion, and the harbouring of revenge revealing the passion still existent in the victim intertwined with the original victimiser. At times, the victim claims she can now express anger against the perpetrator, but when this is in a twisted and vengeful way it is clear that she is still a partner in the old incestuous process.

In group treatment Patricia began to assert herself slowly and in a determined fashion, but only after an initial period of being extremely compliant to the therapist in order to keep the family together. Eventually, she began to express anger, when she was able to scream at another group member and told him to "sod off". She and everyone else was extremely surprised at this and we all experienced a sense of achievement at her newly gained ability to express anger.

However, our reaction was completely different when a few months later we saw her looking extremely elated, radiating a sense of triumph. Although everyone was aware of her mood as soon as she entered the room, nobody felt at ease with this feeling and somebody asked the reason for her feeling so triumphant. Her answer was, "The bastard got what he deserved". At that point everybody knew who she was talking about but nobody knew what she was referring to. Then she said, "The bloody bastard just got to know that his testicles will be removed because of cancer. Isn't that wonderful?".

A few members attempted a smile but most people felt extremely worried about her. I offered her an interpretation dealing with her inability to separate herself from her father in her strong need for revenge. We all know that the expression of anger is therapeutic and a healthy sign, but the wish for revenge is a unhealthy trait which poisons the 
Box 3. Subjects' feelings towards therapist (vertical) and other group members (horizontal)

Victims may appear

Acquiescent

Victim-like

Passive

Sexualised and

eroticised

Afraid/fantasies of Poor motivation for

being seduced and treatment

abused

Feeling guilty

Inability to mourn

Unable to express

anger or revenge
Anti-authority feelings

Rebelliousness

Denial

Lack of insight

Unawareness of

consequences

person who suffers from it and everybody around them as well. This situation revealed how much the victims cling to the perpetrators like a necessary enemy.

Perpetrators initially display defensive mechanisms such as denial and avoidance. Later, with the tolerance and acceptance of other fellow members, perpetrators are able, perhaps for the first time, to look at themselves as abusers in a different light. This can happen only when there is an understanding that blame is the not aim. In his identification with the impotent and helpless victim the perpetrator gets angry on her behalf and demands that she be selfassertive and able to sever herself from her own abusers. In this way, incest victims gain recognition of their own "erotisation of cruelty" (Milton, 1996) and are able to look at problems they are most ashamed of and in need of help with, including the addiction to the abuse and the abuser (van der Kolk, 1989). Artificial idealisation of the victim status is no longer necessary.

\section{Transference}

The subjects are fearful that the therapist, in a oneto-one situation, will lose control, and will fall prey to the subject's seduction, the outcome of which is both hoped for and dreaded. Their underlying anxiety is associated with tremendous fears of separation and being discarded by parental figures if they do not comply with their inappropriate demands. In group therapy they are confronted with reality-testing from their peers, in which the power of being so favoured and unique

(Ganzarain \& Buchele, 1993) has to be worked through in the group situation, a bit like the family, though it operates on very different dynamics. Bentovim (1976, 1991, 1995) has produced extensive and invaluable studies which have highlighted the importance of family dysfunction in the understanding, treatment and management of families with histories of incest.

Incest is very much a matter of family dynamics, it operates on a number of levels simultaneously in different family members including: a discharge of tension between both partners; a degree of satisfaction and sexual gratification where the child is easily available and can be seduced, always in a secretive manner; a discharge of intense hostility; revenge directed towards the female partner through her child; re-establishment of some sort of family dynamics or balance; and disclosure of the secret after a certain point, when incest is no longer necessary to the family dynamics (Welldon, 1988).

\section{Suitability of group analytical psychotherapy}

The combination of incest perpetrators and paedophiles in the same therapy group is thought not to be clinically appropriate, since it can easily lead to serious confusion and disruption of the group dynamics. Other group members immediately notice the consistent difference in attitude of the two different categories of perpertrators and often express a wish to get rid of the paedophiles who are experienced to be the cause of a stalemate in their own treatment. The inclusion of children or young people in these groups is not recommended since this could easily produce emotional disturbances which could be repetitive of the early traumas to youngsters who are not yet emotionally equipped to deal with the strong confrontations that happen in these groups. In the course of group analytical psychotherapy with a group composed of women and men (both genders containing perpetrators and victims of incest) subjects' psychopathologies involve shame, manic defences and primitive defensive mechanisms such as denial, projection and splitting. This tends to divide the helping professions, taking sides for either the victim or the perpetrator, making them forget the neutral stance necessary to understand the whole family dynamics. There is a generation gap in their real and emotional lives in which role reversal has occurred and the group interaction offers a completely different experience. 


\section{Types of group psychotherapy}

\section{Group analysis}

This offers a strict sense of boundaries with awareness of links between acts and unconscious motivations. The interpretation of vertical transference of the group in relation to the therapistparental figures, usually with regressive elements, facilitates independence. Interpretations to do with mixed feelings about peer groups (sibling figures; see Box 2) provide the needed capacity to empathise with others, who actually represent parts of themselves. These are multiple transference processes, which are effectively used for the working through. These are not to be thought of as diluted, since they lead to heightened awareness.

\section{Modified heterogeneity}

In the sense of mixing social and sexual deviancy, this allows for a more comprehensive understanding of all dynamic processes involved, especially those related to their inability to think and their identification with the aggressor who was actually present in their early lives. Victims become aware of the reasons for their lack of trust and their intense need to be in control of all situations.

\section{Single therapist leadership}

Given the nature of the subjects' early deprivation and broken homes, the response to therapists would be one of provocation and humiliation. These people have more skills in breaking-up parental bonding than therapists have in containing their primitive anxieties, intense envy and destructive impulses within the group. Our groups are composed mostly of people who see themselves as victims, experiencing the world as divided into the 'haves' and the 'have nots'. Although the therapist holds the authority, working alone the therapist is seen as unsupported, almost a 'have

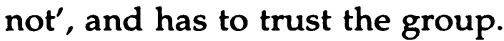

\section{Slow-open groups}

These offer different developmental stages, from dependency to self-assertion, giving opportunities for senior members to take more caring roles confronting junior members in therapeutic ways. It also provides evidence of emotional growth, which is acknowledged by other members and by the therapist facilitating individuality or separation never allowed by uncaring, neglectful parents and never observed in individual therapy. Time is the key to open the most primitive defence mechanisms, and 'short sharp shock' treatment of such complex subjects is doomed to failure.

\section{Conclusion}

Group psychotherapy offers particular advantages as a treatment option for victims of sexual abuse, since secrecy and isolation are replaced by disclosure within the containing atmosphere of the group. The threat of intimacy and the fantasised risks of seduction/exploitation are reduced for both subject and therapist. The power of the group as a whole acts both as an auxiliary ego in strengthening individuals as they confront past pain and abuse, and as a moderator of the sadistic need for revenge that fuels their innate capacity for perpetrating abuse in their turn, thus making it possible to break the cycle.

\section{References}

American Psychiatric Association (1994) Diagnostic and Statistical Manual of Mental Disorders (4th edn)(DSM-IV). Washington, DC: APA.

Ashurst, P. \& Hall, Z. (1989) Understanding Women in Distress. London: Routledge.

Bentovim, A. (1976) Shame and other anxieties associated with breast feeding: a systems theory and psychodynamic approach. In Breast Feeding and the Mother (ed Ciba Foundation), Ciba Foundation Symposium 45, pp. 159-178. Amsterdam: Elsevier.

- (1991) Clinical work with families in which sexual abuse has occurred. In Clinical Approaches to Sex Offenders and their Victims (eds C. R. Hollin \& K. Howells), pp. 179-208. Chichester: Wiley.

- (1995) Trauma-Organised Systems. Physical and Sexual Abuse in Families (revised edn). London: Karnac Books.

Ganzarain, R. \& Buchele, B. (1993) Group psychotherapy for adults with a history of incest. In Comprehensive Group Psychotherapy (eds H. Kaplan \& B. Sadock), pp. 515-525. Baltimore, MD: Williams and Wilkins.

McCarthy, B. (1982) Incest and psychotherapy. Irish Journal of Psychotherapy, 1, 11-16.

Milton, J. (1996) Technical problems in the psychotherapy of perverse female patients. In A Practical Guide to Forensic Psychotherapy (eds E. V. Welldon \& C. Van Velsen), pp. 188193. London: Jessica Kingsley.

Sinason, V. (1991) Interpretations that feel horrible to make and a theoretical unicorn. Journal of Child Psychotherapy, 17, 11-24.

Trowell, J. (1996) The psychodynamics of incest. In A Practical Guide to Forensic Psychotherapy (eds E. V. Welldon \& C. Van Velsen), pp. 33-41. London: Jessica Kingsley.

van der Kolk (1989) The compulsion to repeat the trauma: reenactment, re-victimisation and masochism. Psychiatric Clinics of North America, 12, 389-411.

Welldon, E.V. (1988) Mother, Madonna, Whore: The Idealisation and Denigration of Motherhood (reprinted 1992). London: Free Association Books. 
(1997) The Foulkes Lecture: Group Analysis, pp. 9-26. London: Sage.

\section{Multiple choice questions}

1. Assessment of subjects with perversions:

a can cause unhelpful emotional responses in the professionals

b may be a re-enactment of early family situations

c may lead to the therapist feeling protective of victims

d may provoke punitive feelings towards perpetrators

e requires complete confidentiality from other involved agencies.

2. Secrecy between parent and child:
a is a sign of trust
b leads to the child feeling specially favoured
c permits threatening and violent behaviour
d stifles the ability to think
e is a key pathological trait in incest.

3. Characteristically, paedophiles:

a have presenting problems and circumstances similar to incestuous parents

b involve themselves in child abuse by targeting under-age children c relate well to their peers and also engage in adult relationships

d believe that initiation of children to sexuality by adults is a healthy process

e have better prognosis for treatment than perpetrators of family incest.

4. During psychotherapeutic treatment of incest:

a victims may appear sexualised and eroticised

b victims do not feel guilty

c victims may have fantasies of being seduced

d perpetrators may have poor motivation for treatment

e perpetrators are always aware of the consequences of their actions.

\section{MCQ answers}

$\begin{array}{llll}\text { 1 } & \text { 2 } & 3 & 4 \\ \text { a T } & \text { a F } & \text { a T } & \text { a T } \\ \text { b T } & \text { b T } & \text { b T } & \text { b F } \\ \text { c T } & \text { c T } & \text { c F } & \text { c T } \\ \text { d T } & \text { d T } & \text { d T } & \text { d T } \\ \text { e F } & \text { e T } & \text { e F } & \text { e F }\end{array}$

